\title{
PENDIDIKAN KARAKTER DALAM SASTRA LISAN BETAWOL
}

\author{
Inung Setyami \\ Pendidikan Bahasa dan Sastra Indonesia, FKIP, Universitas Borneo Tarakan \\ inung.setyami@yahoo.com
}

\begin{abstract}
Abstrak
Sastra lisan merupakan salah satu media untuk menerapkan pendidikan karakter. Tujuan Penelitian ini, yaitu untuk mendeskripsikan pendidikan karakter yang terdapat dalam teks sastra lisan Tidung di Tarakan Kalimantan Utara, yaitu cerita Betawol. Sumber data penelitian berupa Cerita Betawol dalam buku Bunga Rampai Cerita Lisan Tidung Kalimantan Utara. Analisis data dilakukan dengan teknik analisis isi (content analysis). Teknik pengumpulan data dilakukan dengan baca catat, yaitu pembacaan disertai dengan pencatatan dengan cermat dan teliti keseluruhan teks berkaitan dengan pendidikan karakter. Penelitian ini merupakan penelitian deskriptif kualitatif. Teknik penelitian dilakukan melalui langkah-langkah 1) identifikasi, 2) pengklasifikasian, 3) interpretasi, dan 4) inferensi. Hasil analisis menunjukkan bahwa Cerita Lisan Tidung Betawol sebagai suatu karya sastra mengandung nilai pendidikan karakter, meliputi: (1) Pendidikan karakter berbasis nilai religious (mempercayai keberadaan Tuhan dan mensyukuri nikmat Tuhan); (2) Pendidikan karakter berbasis nilai budaya (gotong royong, kesenian berupa tarian dan nyanyian, dan tradisi Iraw); (3) Pendidikan karakter berbasis lingkungan (memanfaatkan alam untuk bercocok tanam dan mencari ikan dengan alat tradisional sehingga tidak menimbulkan pencemaran lingkungan); dan (4) Pendidikan karakter berbasis potensi diri (sikap tanggung jawab dan pemberani).
\end{abstract}

Kata Kunci: Pendidikan Karakter, Sastra Lisan, Tidung, Betawol

\begin{abstract}
Oral literature is a medium for implementing character education. The purpose of this study, namely, to describe the character education contained in the oral literary text of Tidung in Tarakan, North Kalimantan, namely the Betawol story. The source of the research data is the Betawol story in the book Bunga Rampai Cerita Lisan Tidung. Data analysis was performed using content analysis techniques. The data collection technique was done by reading notes, namely reading accompanied by careful and thorough recording of the entire text related to character education. This research is a qualitative descriptive study. The research technique is carried out through the steps of 1) identification, 2) classification, 3) interpretation, and 4) inference. The results of the analysis show that the Tidung Betawol Oral Story as a literary work contains character education values, including: (1) character education based on religious values (believing in God's existence and being grateful for God's blessings); (2) Character education based on cultural values (mutual cooperation, arts in the form of dances and songs, and the Iraw tradition); (3) Environment-based character education (utilizing nature for planting and fishing with traditional tools so as not to cause environmental pollution); and (4) character education based on self-potential (responsibility and courage).
\end{abstract}

Keywords: Character Education, Oral Literature, Tidung, Betawol 


\section{PENDAHULUAN}

Pendidikan bukan hanya sekedar mencerdaskan peserta didik secara intelektual saja, namun juga pendidikan sosial, emosional, spiritual dan moral. Hal ini seperti yang diungkapkan oleh Hidayatullah (2010: 6) tujuan dari mendidik dan mengajar pada hakikatnya untuk meletakkan landasan karakter yang kuat melalui internalisasi nilai dalam pendidikan serta menanamkan kecerdasan emosi dan spiritual yang menyertai aktivitas hidup. Pendidikan karakter sebuah upaya untuk membimbing perilaku manusia menuju individu yang berguna baik secara vertical maupun secara horizontal (Anto, 2019: 80). Menurut Asmani (2011:64-65) terdapat empat basis dalam nilai pendidikan karakter, yaitu, (1) pendidikan karakter berbasis nilai religius; (2) pendidikan karakter berbasis nilai budaya; (3) pendidikan karakter berbasis lingkungan; (4) pendidikan karakter berbasis potensi diri. Terkait dengan pendidikan karakter yang perlu ditanamkan oleh pendidik kepada peserta didik, dapat ditempuh dengan berbagai cara dan berbagai media. Salah satu cara dan media yang dapat diterapkan untuk mengaplikasikan pendidikan karakter, yaitu melalui pembelajaran sastra di lingkungan sekolah.

Komariah (2018: 1005) mengungkapkan bahwa pengajaran sastra dapat memberikan sumbangan yang maksimal terhadap aspek-aspek pendidikan susila, sosial, perasaan, sikap penilaian, dan keagamaan. Karya sastra dapat dijadikan salah satu media pendidikan karakter dengan alasan kekuatan bahasa pada karya sastra dapat menyentuh perasaan dalam diri manusia. Hal ini sejalan dengan pernyataan Wibowo (2013: 20) bahwa sastra yang bersifat imajinatif dapat dijadikan media untuk membimbing peserta didik pada keleluasaan berpikir, bertindak, berkarya, pengajaran sastra memiliki potensi untuk menginternalisasikan pendidikan karakter. Demikian halnya pernyataan Ratna (2004: 108) yang menyatakan bahwa sastra memiliki peran yang cukup besar dalam rangka pengembangan pendidikan karakter.

Dapat diketahui bahwa sastra tidak hanya berupa puisi, pantun, prosa (cerpen, novel) dan naskah drama, namun juga berupa sastra lisan. Dengan demikian, sastra lisan juga memiliki potensi sebagai salah satu metode dan media dalam menerapkan pendidikan karakter.

Sastra lisan atau folklor merupakan sebagian kebudayaan kolektif yang tersebar dan diwariskan secara turun temurun, baik dalam bentuk lisan maupun contoh yang disertai dengan gerak isyarat atau alat pembantu pengingat (Danandjaja, 1994: 2). Lebih lanjut, Dananjaya dalam Indonesia Ilmu Gosip Dongeng (1994: 50) menyatakan bahwa dari semua genre folklor, bentuk yang paling dominan diteliti oleh para ahli folklor adalah cerita prosa rakyat, baik mite, dongeng atau legenda. Sementara itu, Finnegan dalam bukunya Oral Poetry (1991) menyebutkan bahwa legenda merupakan cerita prosa rakyat atau tradisi lisan. Dalam pengertian umum, tradisi lisan mengacu pada proses dan produk kultural yang tidak tertulis. Tradisi ini berupa kebiasaan-kebiasaan masyarakat yang telah terbangun dan kepercayaan-kepercayaan atau rutinitas yang dilakukan berulangkali. Kebiasaan tersebut memperlihatkan kontinuitas masa lalu yang tidak melalui tulisan melainkan ucapan/perkataan. Hal ini berarti bahwa tradisi lisan ini mampu menghubungkan generasi masa lalu, masa sekarang, dan masa depan yang diturunkan dari generasi ke generasi.

Sastra lisan adalah kesusastraan yang mencangkup ekspresi kesusastraan warga dan kebudayaan yang disebarkan dari dan diturun-temurunkan secara lisan atau dari mulut ke mulut (Hutomo, 1991:1). Sastra lisan sendiri memiliki nilai-nilai yang luhur dalam masyarakat lebih-lebih pada kebudayaan yang ada dalam masyarakat. 
Cerita lisan yang berkembang dan dimiliki masyarakat penuturnya diyakini memiliki nilai kearifan lokal dan budi pekerti dalam menjaga keselarasan hubungan manusia dengan manusia, manusia dengan Sang Pencipta, dan manusia dengan lingkungan, yaitu menjaga flora dan fauna agar ekosistem tetap terjaga. Pada zaman dulu atau bahkan saat ini, beberapa orang tua masih melakukan aktivitas mendongeng kepada anak-anak sebagai penghangat pengantar tidur yang tentu saja terselip di dalamnya nasihat-nasihat atau pesan moral yang akan disampaikan orang tua kepada anak-anaknya dengan cara yang tidak memaksa dan menghukum. Sebab dengan melalui dongeng, nasihat akan teringat dan menyentuh jiwa batin anak-anak.

Selain itu, terlihat dari banyaknya penelitian terhadap sastra lisan di suatu daerah untuk menggali pesan moral yang ingin diungkapkan maupun pendidikan karakternya. Ruslan (2021: 187) mengungkapkan bahwa di Indonesia tidak terhitung banyaknya sastra lisan yang dijadikan sarana pewarisan nilai-nilai, pengabaran sejarah dan penyampaian hokum untuk ana cucu. Namun demikian, banyak juga cerita lisan dari beberapa daerah di Indonesia yang belum banyak terekspose salah satunya, yaitu cerita lisan Tidung di Tarakan Kalimantan Utara. Oleh sebab itu penelitian terhadap sastra lisan ini perlu dilakukan, yaitu dengan menganalisis secara cermat untuk mengetahui pendidikan karakter apa saja yang terdapat dalam sastra lisan Tidung Betawol dan dapat diaplikasikan dalam kehidupan sebagai bahan pembelajaran.

Sastra lisan Betawol juga pernah dianalisis oleh Erna Wahyuni (2016: 102) dalam artikelnya berjudul membangun karakter anak melalui cerita prosa rakyat berjenis legenda: pengenalan sastra lisan dalam pembelajaran sastra anak di perbatasan Kalimantan Utara. Dalam artikelnya, Erna Wahyuni mengungkapkan bahwa pembelajaran sastra lisan di perbatasan Kalimantan Utara sangat ideal untuk memberikan hasil terhadap pembangunan karakter anak yang diperoleh dengan cara kreatif dengan oleh hati, pikir, rasa, dan raga.

Keunikan sastra lisan Betawol sehingga perlu dilakukan penelitian, yaitu bahwa sastra lisan ini memiliki esensi pendidikan karakter yang layak diketahui dan dijadikan keteladanan hidup. Selain itu, sastra lisan ini belum banyak yang mengkaji dengan demikian perlu dilakukan penelitian berkaitan dengan pendidikan karakter yang terkandung di dalamnya.

\section{METODE PENELITIAN}

Metode yang digunakan dalam penelitian ini adalah metode deskriptif kualitatif dengan sumber data penelitian berupa Buku Bunga Rampai Cerita Lisan Tidung Kalimantan Utara. Buku ini ditulis Inung Setyami dkk. Diterbitan oleh Penerbit Pustaka Abadi tahun 2018. Buku ini memuat 12 cerita lisan Tidung Kalimantan Utara namun dalam penelitian ini hanya diambil 1 cerita, yaitu Betawol. Pemilihan cerita Betawol ini dengan pertimbangan bahwa cerita ini merupakan cerita rakyat Tidung yang tersebar di wilayah Kalimantan Utara dan diduga memiliki pendidikan karakter yang lebih dominan daripada cerita yang lain serta memiliki penceritaan yang lebih panjang. Analisis data dilakukan dengan teknik analisis isi (content analysis). Teknik pengumpulan data dilakukan dengan baca catat, yaitu pembacaan disertai dengan pencatatan dengan cermat dan teliti keseluruhan teks sastra lisan Betawol dalam Buku Bunga Rampai Cerita Lisan Tidung berkaitan dengan pendidikan karakter. Data penelitian ini berupa kata, frase atau kalimat yang memiliki indikator atau berkaitan dengan pendidikan karakter. Pendidikan karakter yang digunakan, yaitu pendidikan karakter yang dikemukakan oleh Asmani (2011:64-65) meliputi (1) pendidikan karakter berbasis nilai religius; (2) pendidikan 
karakter berbasis nilai budaya; (3) pendidikan karakter berbasis lingkungan; (4) pendidikan karakter berbasis potensi diri. Sumber data penelitian berupa cerita lisan Betawol yang terdapat dalam buku Bunga Rampai Sastra Lisan Tidung Kalimantan Utara yang diterbitkan oleh Pustaka Abadi tahun 2018. Penelitian ini merupakan penelitian deskriptif kualitatif. Teknik ini dilakukan melalui langkah-langkah1) identifikasi, 2) pengklasifikasian, 3) interpretasi, dan 4) inferensi.

\section{HASIL DAN PEMBAHASAN}

Sebelum dipaparkan pembahasan mengenai pendidikan karakter dalam sastra lisan Tidung Betawol, berikut disajikan teks cerita lisan Tidung Betawol yang dikutip dari buku Bunga Rampai Sastra Tidung Kalimantan Utara.

BETAWOL

(Cerita lisan suku Tidung di Kalimantan Utara)

Cerita ini merupakan cerita rakyat suku Tidung yang berasal dari daerah Tawau hingga sepanjang daerah Salimbatu. Cerita ini mirip dengan cerita rakyat dari Jawa, yaitu Jaka Tarub yang mengisahkan kisah cinta seorang laki-laki dan bidadari.

Beberapa ribu tahun silam hiduplah seorang pemuda tampan yang biasa di panggil Betawol. Betawol adalah seorang laki-laki atau pemuda gagah yang hingga kini oleh masyarakat Tidung dikenal atau dipercaya sebagai pemuda yang selalu tampak muda dan tak pernah tua. Betawol seorang pemuda desa itu, memiliki kisah yang hingga kini kisah itu selalu diceritakan oleh masyarakat suku Tidung di Kalimantan Utara secara turuntemurun.

Pemuda bernama Betawol ini hidup berdua bersama ibunya. Mereka hidup di suatu kampung berdampingan dengan penduduk yang lain. Warga kampung, demikian juga Betawol dan ibunya, memenuhi hidup dari hasil bertani. Penduduk kampung itu menanam padi dan umbi-umbian untuk kelangsungan hidup sehari-hari. Penduduk kampung ini memiliki kebiasaan bergotong-royong pada masa panen padi tiba. Mereka akan saling membantu satu sama lain. Selain bertani, pekerjaan sehari-hari Betawol adalah mencari ikan. Demikian hidup penduduk di kampung itu, memanfaatkan hasil sungai yang melimpah. Sungai yang panjang dan lebar, menghasilkan berbagai ikan yang bisa dimasak dan untuk menyambung hidup sehari-hari. Setiap waktu, jika musim baik, Betawol pergi ke sungai mencari ikan untuk dijual ibunya di pasar, sebagian untuk lauklauk. Betawol selalu pergi ke sungai membawa Ubu. Ubu ini dipakainya untuk penangkap udang dan ikan, bisa juga kepiting yang terperangkap dalam ubu itu.

Pada suatu hari, Betawol ingin memasang ubunya di pingiran pesisir. Mencari ikan untuk di jual dan untuk lauk di rumah. Pagi hari ia berangkat seorang diri. Ubu yang sudah ia bawa ia tenggelamkan perlahan lahan agar air tidak mengeruh. Setelah ia tenggelamkan, Betawol menunggui ubunya sambil tiduran di perahu yang menepi di pesisir itu. Ubu itu ditungguiya hingga siang sampai ia hampir ketiduran di atas perahu yang ditempatinya. Betawol terkejut karena ubu yang di pasangnya bergoyang-goyang terhempas oleh ombak air pasang di pinggiran pantai. Tiba-tiba salah satu ubu yang di pasangnya hanyut. Ia tak ingin kehilangan ubu yang dipasangnya itu. Ia berharap, ada ikan atau udang dan kepiting terperangkap di dalam ubu itu untuk ia bawa pulang ke rumah.

Dikejarnya ubu yang hanyut itu. Betawol mengejarnya hingga sampai bagian hulu sungai yang sunyi. Di tempat yang sunyi itu, jauh dari orang-orang dan perkampungan, 
ia mendengar suara-suara. Suara-suara kecipak air dan senda gurau yang masih agak tidak jelas bagi pendengarannya. Suara-suara itu ternyata suara gaduh sekumpulan orang yang sedang mandi. Betawol ingin memastikan pendengarannya. Suara gaduh itu semakin lama semakin terdengar jelas oleh telinganya. Betawol semakin penasaran, ia mendengarkan lebih seksama lagi suara itu, yang tak lain ternyata suara itu bersumber dari teriakan riang gadis-gadis cantik yang sedang mandi dan bermain air di danau yang tak jauh dari tempat ia berdiri.

Betawol penasaran, ia ingin lebih mendekat untuk melihat sumber suara itu. Ia bergerak perlahan mendekati arah dari mana asal suara itu. Ditelusurinya perlahan-lahan, disibakkannya dedaunan rimbun sepanjang sungai itu. Ia terperanjat saat matanya melihat ada tujuh gadis cantik yang sedang mandi di sana. Betawol terpesona pada kecantikan gadis-gadis yang tak lain adalah bidadari itu. Lalu timbul niat buruknya, diambilnya salah satu selendang dari beberapa selendang yang teronggok di bebatuan itu. Salah satu selendang itu ternyata milik salah satu bidadari yang sedang mandi di danau itu. Ia sembunyikan selendang itu. Dan ia memulai merencanakan sesuatu.

Usai mandi dan bermain air di danau, bidadari-bidadari itu mengenakan selendangnya hendak pulang ke kahyangan. Mereka menapaki tangga berupa pelangi tujuh rupa. Pelangi tujuh rupa itu hanya muncul sebentar saja dan sebagai jembatan penghubung jika bidadari hendak kembali ke langit atau ingin menuju bumi. Jembatan pelangi yang dinaiki enam bidadari itu pun perlahan memudar kemudian menghilang.

Rupanya ada seorang bidadari yang tetap tinggal. Ia tidak bisa terbang sebab kehilangan selendangnya. Salah satu bidadari yang tetap tinggal karena tak bisa terbang tanpa selendang itu mulai terlihat gelisah dan panik. Tampak kepanikan dan kegelisahan di raut wajahnya, sebab ia tinggal sendiri di danau itu. Semua temannya sudah mulai meninggalkannya menuju kahyangan. Bidadari itu tertinggal seorang diri meratapi kesedihannya. Ke-enam saudaranya telah terbang menuju kahyangan dengan selendang masing-masing. Bidadari yang tertinggal itu menangis seorang diri. Ia tampak begitu sedih. Lalu Betawol muncul untuk menghampiri dan menghiburnya.

Hari semakin senja, pemuda bernama Betawol itu membujuk bidadari itu untuk ikut pulang ke rumahnya. Awalnya bidadari itu enggan, namun Betawol menunjukkan sikap yang baik sehingga bidadari itu pun luluh dan bersedia diajak pulang ke rumah Betawol. Mereka berdua menyusuri sepanjang sungai, meninggalkan danau, dan menerobos hutan untuk memasuki kampung halaman menuju rumah Betawol.

Sesampainya di rumah, ibu Betawol terkejut karena putranya membawa seorang gadis cantik yang belum dikenalnya. Lalu ibunya bertanya, siapa gadis yang bersamanya itu? Dimana mereka berjumpa? Pada awalnya Betawol enggan memberi penjelasan pada ibunya. Namun ibunya terus mendesak sehingga Betawol menceritakan kapan dan dimana bertemu dengan gadis itu.

Hari berganti hari, bulan berganti bulan, rumah Betawol yag sepi kini menjadi ramai dikunjungi para tetangga. Mereka ingin melihat langsung siapa gadis cantik yang selama ini berada di rumah Betawol itu. Betawol memperkenalkan gadis itu dengan nama Dedari. Warga kampung pun kemudian menyebut namanya sebagai Dedari. Pada suatu hari Betawol didatangi tetua adat kampung itu. Tetua adat menyarankan agar Betawol segera menikahi gadis yang tinggal di rumahnya itu, sebab orang kampung akan beranggapan buruk apabila seorang gadis dan bujang yang belum menikah tetapi tinggal serumah.

Berkat dukungan ibu dan saran ketua adat, Bentawol menikahi bidadari itu, karena mereka harus tinggal dalam satu rumah. Dalam pernikahannya, mereka kemudian 
dikaruniai seorang anak perempuan. Sejak kehadiran bidadari itu, hasil panen padi di kampung tersebut menjadi berlipat ganda. Padi tumbuh subur. Pohonnya rimbun dan bulir-bulirnya berisi penuh. Sebagai rasa syukur dengan hasil panen, maka penduduk kampung biasa mengadakan iraw (pesta) selepas panen padi.

Hingga musim panen tiba, warga mengadakan iraw (pesta) panen padi. Kebiasaan masyarakat setiap iraw, yaitu ada makan, minum, menyanyi, dan menari. Ada salah seorang warga yang menyarankan agar istri Betawol yang terkenal kecantikannya itu mau menari di acara tersebut agar parasnya yang cantik dapat dilihat warga kampung pada saat panen padi tiba. Betawol menerima tawaran itu. Namun demikian, istri Betawol bernama Dedari tidak menerima tawaran itu.

Warga kampung itu terus memaksa agar Dedari mau menari di acara iraw panen padi. Karena desakan dari Betawol dan warga kampung, akhirnya Dedari bersedia menari di iraw. Ia mengajukan satu permintaan sebelum dirinya menari, yaitu meminta selendang miliknya yang pernah hilang sewaktu dirinya mandi di danau dulu. Betawol menyanggupi persyaratan tersebut karena terpesona dengan pesta yang akan segera dimulai. Diambilnya selendang Dedari yang sudah disembunyikan di gudang padi itu. Diberikannya pada Dedari untuk dipakai menari.

Dedari terkejut menerima selendang itu. Ia tak menyangka, ternyata selendangnya yang selama ini hilang berada di tangan suaminya. Diterimanya selendang itu. Ia menggunakannya untuk menari. Dedari mulai menari dengan gerakan-gerakan yang gemulai. Tarian yang indah membuat warga kampung yang menyaksikan terpesona. Mereka berteriak kegirangan menyaksikan kecantikan Dedari dan keindahan tariannya. Saat ia menari, melenggak-lenggokkan tubuh, tiba-tiba tubuh Dedari perlahan terangkat ke atas. Kakinya tidak lagi menjejak tanah. Selendang itu membuatnya terbang.

Pesta menjadi begitu riuh saat Dedari terbang semakin menjauh dan tidak turun lagi. Dedari melayang di udara. Melihat itu, Betawol panik. Ia memanggil istrinya berulangkali, namun istrinya diam tak menghiraukannya. Istrinya terbang semakin jauh dan semakin tinggi. Betawol terus mengejar istrinya dan terus memanggil-manggilnya. Dedari terus terbang ke arah laut dan berhenti di atas batu Tenagad. Betawol mengejar istrinya. Ia mendekati batu itu. Ia ingin istrinya kembali. Namun istrinya tidak juga turun. Istrinya tetap berada di atas batu yang menjulang itu.

Akhirnya Betawol mencongkel batu itu dengan suatu alat agar batu itu runtuh dan istrinya bisa turun dan kembali bersamanya. Batu itu ia congkel-congkel hingga cekung terkikis. Belum selesai Betawol mencongkel batu itu, istrinya menghilang. Sebelum istrinya menghilang, ia berpesan pada Betawol:

"Suamiku, jagalah anak kita. Jika kau dan anak kita ingin bertemu denganku, datanglah ke muara sungai Sebuku ketika air laut pasang."

Betawol segera pulang menjemput anaknya. Anak itu dibawanya ke muara sungai Sebuku untuk menunggu istrinya. Pada saat air dalam keadaan pasang, maka datanglah gelombang besar. Tampak Dadari berada di atas gelombang itu. Betawol berteriak memanggil istrinya. Ditariknya tangan anaknya, dan bersama anaknya, Betawol terjun ke air bergelombang besar itu. Betawol dan anaknya lenyap terseret gelombang. Hingga saat ini, di daerah Sebuku Nunukan, ketika air pasang, terdapat gelombang pasang yang oleh masyarakat Tidung di wilayah Sebuku dikenal dengan nama Dulun yang artinya gelombang tujuh lapis atau tujuh tingkat.

Para nelayan di Sebuku akan meminggirkan perahu-perahu mereka saat pasang agar tidak terbalik dan hancur karena terkena hempasan dulun. Dulun di Sebuku ini merupakan fenomena alam tetapi masih ada masyarakat yang mempercayai dan bahkan 
ada cerita yang beredar bahwa orang kampung pernah melihat langsung seorang bidadari berdiri di atas dulun. Batu Tenagad ini ada di Sabah. Bentuk batu ini merongga, cekung di tepiannya (seperti ditebang) karena selalu terhempas badai. Diberi nama batu tenagad karena batu itu tidak bisa di robohkan atau dihancurkan, masih tetap kokoh hingga sekarang. Tenagad artinya tebang (dalam bahasa Tidung). Masyarakat sekitar ada yang memercayai bahwa bidadari cantik masih menunggui batu itu, yaitu Batu Tenagad (Setyami, 2018: 18).

\section{Hasil}

Hasil penelitian menunjukkan bahwa sastra lisan Tidung Kalimantan Utara berjudul Betawol memuat pendidikan karakter menurut Asmani (2011: 64-65) yang akan dijabarkan sebagai berikut (1) Pendidikan karakter berbasis nilai religious (mempercayai keberadaan Tuhan dan mensyukuri nikmat Tuhan); (2) Pendidikan karakter berbasis nilai budaya (budaya gotong royong/tolong menolong, tradisi menari dan menyanyi, dan mengadakan iraw (pesta) sebagai ungkapan rasa syukur); (3) Pendidikan karakter berbasis lingkungan (berkaitan dengan mata pencaharian yaitu bercocok tanam/berkebun dan mencari ikan tanpa menggunakan racun/zat yang membahayakan lingkungan); dan (4) Pendidikan karakter berbasis potensi diri (rasa tanggung jawab dan jiwa pemberani).

\section{Pembahasan}

Pendidikan karakter berbasis religious dalam cerita lisan Betawol ditemukan dalam wujud percaya kepada Tuhan dan mensyukuri nikmat Tuhan. Hal ini ditunjukkan oleh sikap Betawol dan penduduk sekitar yang memiliki rasa syukur atas hasil panen padi yang melimpah. Ditunjukkan pada kutipan teks di bawah ini.

Padi tumbuh subur. Pohonnya rimbun dan bulir-bulirnya berisi penuh. Sebagai rasa syukur kepada Tuhan atas hasil panen yang melimpah, maka penduduk kampung biasa mengadakan iraw (pesta) selepas panen padi dan mengucap rasa syukur kepada Sang Pencipta (Setyami, 2018: 19).

Pendidikan karakter berbasis nilai budaya tampak pada warga masyarakat yang bergotong royong/tolong menolong, tradisi menari menyanyi, mengadakan Iraw atau pesta sebagai ungkapan rasa syukur kepada sang pemberi rejeki. Apa yang terealisasi dalam cerita lisan Betawol merupakan refleksi kehidupan masyarakat suku Tidung yang memunculkan cerita lisan tersebut. Hal ini dapat dilihat adanya tradisi budaya Iraw yang terdapat dalam cerita lisan betawol. Dalam kehidupan nyata masyarakat Tidung Kalimantan Utara juga mengenal tradisi Iraw. Tradisi Iraw merupakan bagian dari kebudayaan luhur yang dilakukan tiap tahun hingga kini.

Di Kalimantan Utara khususnya di Tarakan terdapat tradisi Iraw Tengkayu. Iraw Tengkayu merupakan kata dari bahasa Tidung. Iraw berarti pesta atau perayaan. Sedangkan Tengkayu berarti pulai kecil. Dalam hal ini Tengkayu merujuk pada kota kecil di Kalimantan Utara, yaitu Kota Tarakan.

Iraw Tengkayu merupakan warisan adat suku asli Tidung yang dilaksanakan dengan tujuan bentuk rasa syukur atas rejeki dari Tuhan (baik rejeki panen dari laut dan tanah). Tradisi ini biasanya dilakukan di pinggir laut (di Kota Tarakan dilakukan di Pantai Amal dengan menghadirkan penari kolosal dengan pakaian tradisional. Upacara tradisional ini dilakukan dengan menghanyutkan sesaji yang ditaruh di dalam perahu ke laut dan gelaran perlombaan. Diawali dengan doa bersama sebagai wujud syukur, 
kemudian pawai mengiringi padaw tujuh dulung, yaitu sebuah perahu dengan tujuh haluan sebelum akhirnya perahu dilarung ke Pantai. Dengan demikian, realitas ekstratekstual yang muncul dalam cerita Betawol merupakan refleksi kehidupan masyarakat suku Tidung yang menjadi gambaran pendidikan karate berupa rasa syukur. Ditunjukkan pada kutipan di bawah ini.

Hingga musim panen tiba, warga mengadakan iraw (pesta) panen padi. Kebiasaan masyarakat setiap iraw, yaitu ada makan, minum, menyanyi, dan menari. Ada salah seorang warga yang menyarankan agar istri Betawol yang terkenal kecantikannya itu mau menari di acara tersebut agar parasnya yang cantik dapat dilihat warga kampung pada saat panen padi tiba. Betawol menerima tawaran itu. Namun demikian, istri Betawol bernama Dedari tidak menerima tawaran itu. Warga kampung itu terus memaksa agar Dedari mau menari di acara iraw panen padi. Karena desakan dari Betawol dan warga kampung, akhirnya Dedari bersedia menari di iraw. Ia mengajukan satu permintaan sebelum dirinya menari, yaitu meminta selendang miliknya yang pernah hilang sewaktu dirinya mandi di danau dulu. Betawol menyanggupi persyaratan tersebut karena terpesona dengan pesta yang akan segera dimulai. Diambilnya selendang Dedari yang sudah disembunyikan di gudang padi itu. Diberikannya pada Dedari untuk dipakai menari (setyami, 2018: 20).

Pendidikan karakter berbasis lingkungan dalam cerita lisan Betawol, yaitu menampakkan kehidupan mendayagunakan alam diantaranya bertani/berkebun dan mencari ikan. Dalam cerita Betawol, pencarian ikan digambarkan dengan alat yang ramah lingkungan dan tidak menyebabkan kerusakan, yaitu dengan alat pencari ikan tradisional ubu. Dalam cerita digambarkan, Betawol menggunakan alat tradisonal ubu untuk mencari ikan, udang, dan kepiting di sungai (tidak menggunakan bahan yang dapat mencemari alam dan membahayakan kehidupan eksosistem perairan). Selain itu, pencarian ikan digambarkan dengan alat perahu. Hal ini tentu berkaitan dengan kehidupan masyarakat Tidung yang tidak terlepas dari perahu dan bercocok tanam. Hal ini ditunjukkan pada kutipan di bawah ini.

Penduduk kampung ini memiliki kebiasaan bergotong-royong pada masa panen padi tiba. Mereka akan saling membantu satu sama lain. Selain bertani, pekerjaan sehari-hari Betawol adalah mencari ikan. Demikian hidup penduduk di kampung itu, memanfaatkan hasil sungai yang melimpah (Setyami, 2018: 18).

Betawol selalu pergi ke sungai membawa Ubu. Ubu ini dipakainya untuk penangkap udang dan ikan, bisa juga kepiting yang terperangkap dalam ubu itu (Setyami, 2018: 19).

Terakhir, pendidikan karakter berbasis potensi diri yang meliputi kepedulian dan rasa tanggung jawab. Hal ini digambarkan pada tokoh Betawol yang memiliki tanggung jawab untuk menikahi bidadari karena anjuran dari ketua adat dan ibunya. Dalam cerita digambarkan pesan moral sederhana yang bermakna bahwa "tidak boleh tinggal serumah jika belum menikah". Sebab Betawol telah membawa pulang bidadari bernama Dedari dan mereka tinggal serumah, maka ketua adat meminta Betawol untuk menikahi Dedari. Berkaitan dengan kehidupan Suku Tidung, hal ini merupakan pelajaran tentang moral. Suku Tidung yang sebagian besar beragama Islam mengenal tentang larangan zina. Hidup 
serumah antara lainnya dan perempuan yang bukan muhrim dapat dikatakan mendekati atau berzina yang dalam agama Islam merupakan dosa besar. Sebagai pesan moral, hal ini dihadirkan dalam wujud cerita lisan sebagai pesan. Terlihat pada kutipan berikut.

Warga kampung pun kemudian menyebut namanya sebagai Dedari. Pada suatu hari Betawol didatangi tetua adat kampung itu. Tetua adat menyarankan agar Betawol segera menikahi gadis yang tinggal di rumahnya itu, sebab orang kampung akan beranggapan buruk apabila seorang gadis dan bujang yang belum menikah tetapi tinggal serumah. Berkat dukungan ibu dan saran ketua adat, Bentawol menikahi bidadari itu, karena mereka harus tinggal dalam satu rumah (Setyami, 2018: 20).

Terdapat pesan sederhana yang sangat bermakna dari cerita lisan Betawol, yaitu mengambil sesuatu yang bukan miliknya aan mengakibatkan seseorang harus menerima jika kehilangan lebih besar lagi. Hal ini tampa dari sikap Betawol yang mengambil selendang bidadari yang pada akhirnya membuat Betawol kehilangan Dedari yang telah dicintainya.

\section{SIMPULAN}

Sastra lisan yang 'hidup' di lingkungan masyarakat menjadi alat penyampai pesan moral pada suatu kelompok masyarakat. Hal ini karena sastra lisan tersebut memuat pendidikan karakter yang dapat digunakan sarana sebagai media untuk mengantarkan dan mewujudkan masyarakat dalam kehidupan yang bermartabat. Demikian halnya sastra lisan Tidung di Kalimantan Utara yang terkumpul dalam buku Bunga Rampai Sastra Lisan Tidung Kalimantan Utara. Hasil penelitian menunjukkan bahwa Cerita Lisan Tidung sebagai suatu karya sastra mengandung nilai pendidikan karakter yang meliputi: (1) Pendidikan karakter berbasis nilai religious (mempercayai keberadaan Tuhan, mensyukuri nikmat Tuhan); (2) Pendidikan karakter berbasis nilai budaya (pengobatan tradisional dan budaya gotong royong); (3) Pendidikan karakter berbasis lingkungan (cinta lingkungan menjaga alam binatang dan tumbuhan); dan (4) Pendidikan karakter berbasis potensi diri (meliputi tanggung jawab, kepedulian, kasih sayang).

\section{DAFTAR PUSTAKA}

Anto. P., \& Anita. T. (2019). Tembang macapat sebagai penunjang pendidikan karakter. DEIKSIS, 11(1), 80. DOI: 10.30998/deiksis.v11i01.3221.

Asmani, J. M. (2011). Buku panduan internalisasi pendidikan karakter di sekolah. Yogyakarta: Diva Press.

Danandjaya, J. (1994). Folklor Indonesia ilmu gosip, dongeng, dan lain lain. Jakarta: Pustaka Utama Grafiti.

Finnegan, R. (1991). Oral poetry: Its nature, significance, and sosial contents. Bloomington: Indiana University Press.

Harun, C. (1984). Sastra sebagai human control. In: Dua Puluh Sastrawan Bicara. Jakarta: Sinar Agape Press, 42-50.

Hidayatullah, F. (2010). Pendidikan karakter: Membangun peradapan bangsa. Surakarta: Yuma Pustaka.

Hutomo, S. S. (1991). Mutiara yang terlupakan: Pengantar studi sastra lisan. Surabaya: Hiski Jawa Timur. 
Kementerian Pendidikan Nasional (2011). Panduan pelaksanaan pendidikan karakter. Jakarta: Kementerian Pendidikan Nasional.

Komariah. (2018). Pengembangan bahan ajar cerita rakyat Kuningan terintegrasi nilai karater dalam pembelajaran apresiasi sastra di SMP. Deiksis Jurnal Pendidikan Bahasa dan Sastra Indonesia, 5(1), 100-110.

Ratna, N. K. (2014). Peranan karya sastra, seni dan budaya dalam pendidikan karakter. Yogyakarta: Pustaka Pelajar.

Ruslan, R., Sugono, D., \& Suendarti, M. (2021). Aspek Stilistika dan Nilai Moral dalam Novel Ayah, Aku Rindu Karya S. Gegge Mappangewa. DEIKSIS, 13(2), 186-196.

Setyami, I. (2018). Bunga Rampai Cerita Lisan Tidung Kalimantan Utara. Jember: Pustaka Abadi.

Wahyuni, E. (2016). Membangun karakter anak melalui cerita prosa rakyat berjenis legenda. Pengenalan sastra lisan dalam pembelajaran sastra anak di perbatasan Kalimantan Utara. Balai Bahasa Daerah Istimewa Yogyakarta. Tidak terdapat nama jurnal.

Wibowo, A. (2013) Pendidikan karakter berbasis sastra. Yogyakarta: Pustaka Pelajar. 